\title{
Designer's emotions in the design process
}

\author{
BIAGIOLI Monica ${ }^{a *}$; GRIMALDI Silvia ${ }^{a}$, and ALI Hena \\ ${ }^{a}$ London College of Communication, University of the Arts London \\ ${ }^{\mathrm{b}}$ University of Westminster \\ * Corresponding author e-mail: m.biagioli@lcc.arts.ac.uk \\ doi: $10.21606 / d m a .2017 .408$
}

This is a position paper towards the establishment of a research network to address the impact of tacit experiential knowledge, emotion, and cultural perspective on a designer's decision-making during a design process. With this network, we are aiming to start a focused discussion across geographies and cultures regarding the role and impact of designers' emotions within their own design process. The function of this is to foreground the experiential and emotional domain of designers' practice and examine the role of tacit experiential knowledge in design decision-making.

The paper sets up the basis and context of discussion, exploring the three key areas to be addressed by the network: designers' emotions as key drivers in decisionmaking; tacit experiential knowledge; and addressing emotion in culturally-situated design practice. This is followed by our proposed methodology and network objectives and expected impact and outcomes.

design process, emotion, culturally-situated practice, tacit experiential knowledge

\section{Introduction}

This position paper outlines the proposal for an international research network of design academics and industry specialists to highlight the importance of non-textual, narrative, qualitative methods and forms of expression to represent as well as foreground emotional and experiential aspects of designers' engagement within a design process.

There are two key questions driving our research. Can we explicitly account for designers' emotions during a design process? And can we demonstrate any links between designer emotion and decisionmaking in a design process? If we can, as designers, access this type of tacit information-belonging in the informal realm, characterised by complexity and ambiguity, and expressed as emotion-then its impact on rational decision-making can be acknowledged.

We are focussing on the designer's emotions and experience within a design process as the designer is often considered a neutral person within the process. However, from our teaching experience, 
design students have complex relationships with their project especially when they tackle "wicked problems" (Buchanan, 1992; Rittel \& Webber, 1973). Some of these projects generate strong emotions and feelings in the designer, such as empathy, sadness, anger or a feeling of empowerment, and this has a bearing on the project outcomes. We are drawing attention to qualitative methods because they allow for gathering information, such as tacit experiential knowledge and emotional states, that would not be visible in data set analysis, however, has impact on project planning, engagement and outcomes. The research work we propose aims to help the designer identify key emotions at play at different stages of a project or activity. In addition, we will examine how designers' emotions play a role in how the project is structured and delivered and how the findings are collated and interpreted.

We are building our approach to the network and its methods from an understanding about cultural transmission of information (formal, informal, technical; Hall, 1959), the impact of our data-driven reality on human communication (Boorstin, 2012; Marshall McLuhan, 1994) and how that has a direct effect on our sense of embodiment (Dewey, 2005; Laing, 2010). We connect the difficulty to base decisions on qualitative forms to a lack of trust generally in the informal realm-particularly emotions - to impart useful information in regards to decision-making (Belfiore \& Bennett, 2008; McGilchrist, 2009). An appreciation and respect for the tacit dimension (Gill, 2015; Ingold, 2000; Polanyi, 2009; Schön, 1985) is a key aim of the work we propose for this network.

The project is proposed with a short-term (first phase) and long-term engagement plan. The research network will form the first phase of the longer project. In this first phase we will be inviting participants to two discovery workshops and one dissemination event. These workshops and events will be held in London over the course of 18 months, from Summer 2018.

The diverse participant group draws knowledge across disciplines and geographies to get a more rounded picture about emotion and its impact on the design process. The initial call for interest has drawn a group of 20 participants from Pakistan, Brazil, U.S.A., Israel, Finland, Spain, Denmark, and the UK. Adopting a democratic and participatory structure to the network sessions will, as much as possible, seek knowledge from sites of experience outside of the UK. Participant expertise spans across different subject areas and contexts, including academics and industry representatives in service design, product design, British Council Pakistan, workshop facilitation, graphic design, fashion, business and management, innovation, transdisciplinary art, teaching and learning, and IT.

The first workshop will address the three main themes: emotion, tacit knowledge and cross-cultural participation.

Designers make tacit experiential decisions at every stage of the design process. Emotions such as empathy, anger and fear in relation to a particular topic, circumstance, or grouping can trigger responses that influence a design process. The role designers' emotions play in this process is not often made explicit, despite the important function emotions play in decision-making. This has implications for the role of the designers' emotions in design decisions. Human-Centred and Emotional Design (Forlizzi, 1997; Hassenzahl, 2010; Jordan, 2000; McDonagh, Hekkert, Erp, \& Gyi, 2003; Norman, 2003; Sanders \& Stappers, 2008; Wright \& McCarthy, 2008) often focus on end users' emotions, however the emotions of designers and facilitators within co-design situations are not acknowledged as often. The informal, the non-textual, the narrative and the emotional that exist in the liminal space between formal analysis of data and formal design decision-making are not accounted for qualitatively and/or made explicit.

Qualitative design and art based methods have a particular value for accessing informal, non-textual, narrative, and emotional elements and making them tangible. These qualitative design methods are often applied to researching the end users' emotions, but rarely are they used to look inwards towards the designers themselves. 
Emotion is in the informal domain and accounting for its role in a decision-making situation requires an acknowledgement of embodied experience. There is a current bias towards quantitative forms of collecting and analysing experience in order to make the case for making decisions which omit findings from the informal experiential range, as they are so difficult to quantify.

Through the research network, we will draw knowledge across disciplines and geographies to get a more rounded picture about designers' emotions and their impact.

\section{Emotion, Tacit Knowledge and Cross-cultural Participation in the design process}

\subsection{Section 1: Designers' emotions as key drivers in decision-making}

Emotions have a troubled history. Within western contexts, emotions have been for centuries contrasted with reason as two separate driving forces of human nature, with an implicit or explicit value judgement about which force holds more value (Damasio, 2000; Lutz, 1986). From a cultural point of view, emotions have been used as a way to judge "others" whether those "others" are women, or people from different cultures, or from different classes. "To look at the Euroamerican construction of emotion is to unmask the ways in which that schema unconsciously serves as a normative device for judging the mental health of culturally different peoples" (Lutz, 1986, p. 288). Within this context, this dichotomy also allows to maintain a system of power relations based on this ideological distinction (Lutz, 1986).

Because of this distinction, the studies on emotion from a scientific perspective are still at the beginning. There is a clear gap in the study of emotion between Darwin's studies in 1872 (Darwin, 1998), widely considered the first scientific studies on emotion, and the 1960s, in which very little was written about emotions from a scientific point of view. This can be attributed to the fact that emotion was not considered, for most of the last century, to be a worthy subject, and was left in the background in favour of reason. Emotion was "relegated [...] to the lower neural strata associated with ancestors whom no one worshipped. In the end, not only was emotion not rational, even studying it was probably not rational." (Damasio, 2000, p. 39). This view still dominates the scientific framework for the study of emotions, and there is still very little study of emotion from a scientific perspective. With the advent of psychology and psychotherapy (the thinking of Freud and Jung dominating the development of thinking into the $20^{\text {th }}$ century), other sciences started to advance theories about emotions and viewing them as inseparable parts of our mental process, working in symbiosis with the part we call reason.

Antonio Damasio is a neurologist who pioneered the study of emotion and their effect on human consciousness by studying patients with brain damage in the emotional areas of the brain. He has shown that emotions are necessary to run a regular life and have particular implications for decisionmaking. Individuals who have brain damage in areas of the brain related to emotions seem unable to make 'rational decisions' and will make "personal and social decisions [that] are irrational, more often disadvantageous to their selves and to others than not." (Damasio, 2000, p. 40). This clearly challenges the cultural idea that emotion and rationality are two contrasting forces, and in fact theorises that emotion is necessary for rational decisions to take place.

Scientifically, emotions are chemical and neural responses to stimuli from the outside or from memory, and they have a regulatory function within the body. This function has a number of implications for the physical state of the person and for the person's state of mind. By changing the mental state of a person, they make the person experience what is around them in a different way and make a mental association between the particular stimulus (object or event that caused the emotion) and the emotion felt (Damasio, 2000, 2006). The emotional state that was associated with 
the stimulus will be remembered whenever the person is thinking of that particular stimulus or whenever this is encountered again.

This has implications for the decision-making aspects inherent in tacit knowledge. One very interesting study looks at the decision-making of a psychotherapist in a consultation with patients who have attempted suicide. The psychotherapist's written assessments on whether the patient was likely to re-attempt suicide were not reliable in predicting this risk ( $29 \%$ accuracy). However, an analysis of the psychotherapist's facial expressions, with a method devised by Ekman et al (Ekman, Friesen, \& Tomkins, 2009) which codes facial expressions against emotions, revealed that frowns and worried facial expressions in the psychotherapist were a much more accurate assessment of this risk ( $81 \%$ accuracy). This was also compared to a study of the patient's micro-expressions in the same interaction, which did not lead to a method of coding these expressions that was as reliable to predict suicide reattempt. The psychotherapist was therefore able to read the tacit communication from the patient better than an algorithm, and interpret this in an instinctual and emotional way (Heller \& Haynal, 2002). This type of study is still quite rare across many fields, not least because of the complexity of coding the information; however, it is a prompt towards thinking about the tacit and emotional knowledge that humans bring to their decision-making.

Human-Centred and Emotional Design (Forlizzi, 1997; Hassenzahl, 2010; Jordan, 2000; McDonagh et al., 2003; Norman, 2003; Sanders \& Stappers, 2008; Wright \& McCarthy, 2008) often focus on end users' emotions, however the emotions of designers are not acknowledged as often. Within craftbased design practices this approach has been increasingly valued; for example Niedderer \&Townsend, Mäkelä and Nimkumrat and Kosoken \& Mäkelä talk about experiential and emotional knowledge within craft-based design processes, and how this reflection can be documented through design based methods (Kosonen \& Mäkelä, 2012; Mäkelä \& Nimkulrat, 2011; Niedderer \& Townsend, 2014). Seitamaa-Hakkarainen et. al discuss the role of autoethnography in documenting designers' working processes (Seitamaa-Hakkarainen, Laamanen, Viitala, \& Mäkelä, 2013). Groth examines the links between emotion and decision making as well as tacit knowledge and embodied cognition in craft making processes (Groth, 2016). Anne Louise Bang reflects on the design process, in particular in terms of emotion and tacit knowledge, outside of a strictly craft-based setting within the textile design field (Bang, 2009, 2011). While these approaches are valuable to this research, they have not been commonly applied to researching the emotions and tacit knowledge of designers within a co-design situation, and in relation to designers' roles within an organisational context .

\subsection{Section 2: Tacit experiential knowledge}

As the world of work evolves to make room for robotic components and algorithmic computation to input into decision-making and realise more and more complex tasks, it is increasingly important to consider the organization's view of their workers as embodied persons.

Giovanni Schiuma argues that "organizations have to be managed as 'living organisms' in which the people and the organizational aesthetic dimensions are recognized as fundamental factors to meet the complexity and turbulence of the new business age." (Schiuma, 2011, p. 2) For that, Edward T. Hall's diagram of human activity is highly relevant. He deduced a system of understanding human activity in three porous layers: formal, informal, and technical (Hall, 1959). The formal layer is occupied by expectations, values and structures; those values and structures are shaped into more codified forms (rituals, language, protocols) in the technical layer; and the informal layer is where shifts can happen and is the terrain of gesture, play, informal learning, and a sense of individual space and beliefs.

It follows that accounting for the informal requires an acknowledgement of embodied experience. As John Dewey explained it: "Experience is the result, the sign, and the reward of that interaction of 
organism and environment which, when it is carried to the full, is a transformation of interaction into participation and communication." (Dewey, 2005, p. 22). For Dewey, there were complete experiences, holding transformative and aesthetic potential and characterised by feelings of satiety and fulfilment, and inchoate experiences, obstructed by distraction and dispersion. The many layers of diversion and entertainment broadcast from various media sources create a level of inertia that Daniel Boorstin identified over 50 years ago as visual gauze, at the time when mass media lodged into the North American consciousness. This disjunction between what is communicated (and how) and what is experienced leads then to more frequent inchoate experiences; dispersed and incomplete.

The result, as lain McGilchrist identifies, are various current maladies: "loss of tolerance of ambiguity; the carrying out of procedures by rote without understanding; de-individualisation; paranoia and lack of trust; a worship of the quantitative and devaluation of quality; and downgrading of expertise and its capacity to react with spontaneity and creativity in favour of 'expert' knowledge that can be pre-determined" (Holmes, 2012, p. 163). This loss of faith in more holistic, embodied forms relates to our current means of communication that shape as well our sense of identity (M. McLuhan, 1964).

In their book on the social impact of the arts, Belfiore and Bennett account for our growing reliance on evidence to make the case for policy; with "hard data, such as facts, trends and survey information...widely seen as the 'gold standard'" (Belfiore \& Bennett, 2008, p.5). The subtext riding below the surface of this approach is that qualitative forms of analysis cannot be trusted to formulate decisions. Satinder Gill sees it as a situation where "the paradigm of data (of parts) and utility gives primacy to transactional information over that which is relational." (Gill, 2015, np). She addresses "the problems of bottlenecks of vast quantities of data and how to relate to them (expert systems, databases, big data), and how to support our relations with each other and share and enable us to impart knowledge and skills when we are distributed in space via various mediating interfaces" (Gill, 2015, np).

As Michael Polanyi cautions, "if we build up a culture recklessly on the assumption that only things are valid which can be broken into parts - and that the putting together will take care of itself - we may be quite mistaken, and all kinds of things may follow." (Polanyi, 1989, quoted in (Gill, 2015, np)) Drawing attention to qualitative methods and more explicitly accounting for tacit experiential knowledge and emotional states-not just in participants and end users but also in designers and facilitators - can address this imperative to consider societal problems and needs holistically.

\subsection{Section 3: Addressing emotion in culturally-situated design practice}

Participatory design practice can be explored within specific groups. Multicultural research that situates itself across diverse cultural practices benefits from this method in particular to understand the phenomenon of knowledge creation and designers' decision-making processes as a whole (Björgvinsson, Ehn, \& Hillgren, 2010; Sanders \& Stappers, 2008). Here cultural context is defined as values and attitudes that shape the context (Mondoux, 2010). Where culture creates the context for social interaction to determine how knowledge will be used in particular situation (Long \& Fahey, 2000).

Models of decision-making usually focus on cognitive, situational, and socio-cultural variables in accounting for human performance. However, the emotional component is rarely addressed within these models (Gutnik, Hakimzada, Yoskowitz, \& Patel, 2006). According Polanyi (Polanyi, 2009) understanding how people feel gives us the ability to empathize with them; tacit knowledge can reveal latent needs, i.e., needs not recognizable until the future Hence, discovering what people think and know provides us with their perceptions of experience (Sanders \& Stappers, 2008). We may be overwhelmed by emotions and make decisions or we choose an option not so much because 
we evaluate its consequences positively, but because we feel good about it; we may even be torn apart between emotions and cognitions, as in the proverbial conflict between heart and mind (Duque, Turla, \& Evangelista, 2013).

However, with data driven innovation and tech revolution overtaking the world, design as a creative discipline and designer as a creative actor (Latour, Mauguin, \& Teil, 1992; Law, 1992) is floundering in this tug of war between data, technology and emotional intelligence defined as a set of skills hypothesised to contribute to the accurate appraisal and expression of emotion in oneself and in others, the effective regulation of emotion in self and others, and the use of feelings to motivate, plan, and achieve in one's life (Salovey \& Sluyter, 2001). Although, brands may need data to understand human emotion, they also need humans to understand the emotional data that will help them maximise effectiveness, as humans, not robots, create emotional bonds. Emotions are important as key drivers for value mapping of actors, networks to explore decision-making processes within specific design contexts as existing networks and drivers (Latour et al., 1992). However, for participatory design projects to be successful designers need ". . . not only to analyse existing actor networks but ultimately to redesign them in ways that help establish and maintain participative structures" (Kensing \& Blomberg, 1998) as well as solve problems. The most common application of tacit knowledge is to problem solving. According Leonard \& Sensiper (Leonard \& Sensiper, 1998) the reason experts on a given subject can solve a problem more readily than novices is that the experts have in mind a pattern born of experience, which they can overlay on a particular problem and use to quickly detect a solution. "The expert recognizes not only the situation in which he finds himself, but also what action might be appropriate for dealing with it.

Neuro-economics is applied as evidence for the emotional aspect of decision-making and its role as a new framework of investigation, as it builds a comprehensive theory of decision-making through the unification of theories and methods from economics, psychology, and neuroscience. Even though this approach promises to be valuable as a comprehensively descriptive and possibly better predictive model for construction and customization of decision support tools for health professionals and consumers, there is ambiguity in its usefulness for designers who are designing these tools (Gutnik et al., 2006).

Contrarily, drawing on Actor Network Theory (Latour, 2007; Latour et al., 1992) participatory design practice (Björgvinsson et al., 2010; Sanders \& Stappers, 2008) bridges knowledge gap within diverse contexts (Bonnet, Lema, \& Auken, 2010; Cheryl Mattingly, 2000) by creating immersive knowledge mapping spaces, and facilitating development of narrative expressions of social knowledge. In this model, it is human narrative that draws a bridge between the tacit and the explicit, allowing tacit social knowledge to be demonstrated and learned [...]. In addition, narrative in the expression and transmission of social knowledge, is a specific type of tacit knowledge, and defines a new perspective for designing and developing interactive systems to support collaborative knowledge management.

The key concept here is to involve domain experts in participatory knowledge design for mapping and translating their professional models into the proper vocabularies, notations, and suitable visual structures for navigating among interface elements (Valtolina \& Colombo, 2012). Participation brings in narrative as a central mechanism, by which social knowledge is conveyed (Linde, 2001) and emotions are mapped as culturally situated values and decision-making drivers, as knowledge is understood as is inherently complex and dynamic across contexts, strategies and identities (Williams, 2006).

\section{Proposed methodology}

As part of this research network will be inviting participants to two discovery workshops and one dissemination event over the course of 18 months. The participant group draws knowledge across 
disciplines and geographies to get a more rounded picture about emotion and its impact on the design process. The makeup of the group is detailed in the introduction; we invited researchers and practitioners who we knew had worked in the field of emotions, tacit knowledge and cross-cultural participation, and who, from previous conversations and previous collaborations, we thought would have an interest in this topic. In particular, we tried to draw people who had worked on emotions, tacit knowledge and cross-cultural participation in relation to problem-setting and wicked problems.

The first workshop will address the three main themes: emotion, tacit knowledge and cross-cultural participation, making use of qualitative art and design methods to:

- Test various spatial and relational configurations that allow embodied experience to emerge as key finding from informal experience. Evolving methods for accounting for the informal in a situated experience.

- Note and capture tacit experiential emotional responses in our research network in tandem with the capture of data of network participants' personal values and attitudes. Analysis of this data will be conducted to evolve a means of understanding the relationship between what is expressed as personal value and attitude and what is textually recorded as personal values and attitudes.

- Note and capture emergent human narratives: discovering what people think and know provides us with their perceptions of experience.

- Test methods of documenting and visualising emotional experience throughout the design process and its possible links to decision-making.

At this stage, we hope to identify 'where, when and how' within design process are significant points of interests for designers accounting for their own emotions. This process of learning shall evolve valuable insights and identify challenges within existing and new design practices.

The second workshop will provide spaces for contributions by participants around the themes of the project, as well as methodological contributions to gathering and analysing data. The aim of the workshops is to construct a democratized design space to engender an open mind set. In addition, opening up the workshop to methodological contributions will help to assess the validity of the methods used, and test innovative methods coming from culturally and geographically diverse regions, and different disciplinary contexts.

The exploration is perceived as valuable in terms of identifying emotional triggers, challenges and recharging points within design practice for designers' emotions as design confidence and wellbeing. This in retrospect impacts the collaborative project outcomes operationally. Accounting for designers' emotions can lead to balancing stress, facilitating the feeling of being in charge of things, and identification of motivators to push into action. Enquiring from a socio-cultural perspective, the aim is to realise a comprehensive database as baseline to work up from. This shall help ascertain effective design tools to map designers' emotions and develop a rich repository of perspectives. This can lead to effective working and collaborative initiatives where the designer's wellbeing is accounted for as central to project sustainability.

The dissemination event will then broadcast the findings as well as provide a platform for more voices to shape a future project.

\section{Network Aims, Objectives, Impact and Outcomes}

The proposed aims, objectives and impact address 5 main thematic areas: The role of emotions in the design process; Qualitative methods to record emotions; New discourse about the design process; Application of tools to understand users' emotions to the understanding of designers' emotions; Representing the diversity of participants. 


\begin{tabular}{|c|c|c|c|}
\hline THEMES & AIMS (what?) & OBJECTIVES (how?) & $\begin{array}{l}\text { IMPACT (who cares? What } \\
\text { happens? So what?) }\end{array}$ \\
\hline 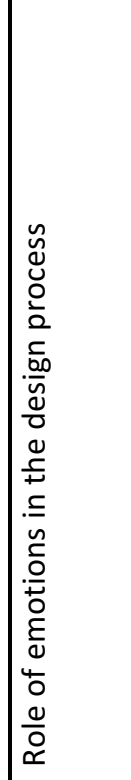 & $\begin{array}{l}\text { Specify the role of emotions } \\
\text { in decision-making within } \\
\text { design processes. } \\
\text { Define what is valuable } \\
\text { information in the design } \\
\text { process for the designer. }\end{array}$ & $\begin{array}{l}\text { To create a clear link between } \\
\text { design process and emotion } \\
\text { Provide templates for } \\
\text { designers to map and track } \\
\text { their emotions against a } \\
\text { project timeline. }\end{array}$ & $\begin{array}{l}\text { Develop an index of potential } \\
\text { tools and techniques to help } \\
\text { the designer account for type, } \\
\text { timing and sequence of } \\
\text { emotions during a project, not } \\
\text { just for participants but also } \\
\text { for him/herself. } \\
\text { Provide templates for } \\
\text { designers to map and track } \\
\text { their emotions against a } \\
\text { project timeline. } \\
\text { Provide tools to address } \\
\text { difficult projects and how to } \\
\text { advise people to account for } \\
\text { difficult emotions during a } \\
\text { decision-making process that } \\
\text { is in blockage, stasis or } \\
\text { breakdown. }\end{array}$ \\
\hline 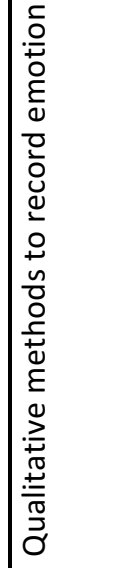 & $\begin{array}{l}\text { - Highlight the value of } \\
\text { qualitative design methods to } \\
\text { access and record emotions, } \\
\text { and make these tangible. } \\
\text { This can help identify } \\
\text { qualitative methods to access } \\
\text { the non-textual, the narrative } \\
\text { and the emotional forms of } \\
\text { expression to represent and } \\
\text { foreground emotional and } \\
\text { experiential aspects of } \\
\text { designers' engagement with } \\
\text { a design process. }\end{array}$ & $\begin{array}{l}\text { Draw knowledge across } \\
\text { disciplines and geographies to } \\
\text { get a more rounded picture } \\
\text { about emotion and its impact. } \\
\text { Towards that end, we have } \\
\text { put together a team of } 20 \\
\text { participants from Pakistan, } \\
\text { Brazil, U.S.A., Israel, Finland, } \\
\text { Spain, Denmark, and the UK: }\end{array}$ & $\begin{array}{l}\text { A new index of qualitative } \\
\text { methods that can address } \\
\text { designers' emotion and are } \\
\text { design specific. }\end{array}$ \\
\hline 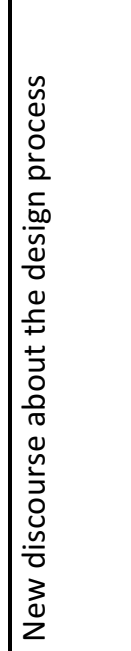 & $\begin{array}{l}\text { Identify a new discourse } \\
\text { about design process that } \\
\text { takes into account the } \\
\text { designer's emotion as a focal } \\
\text { point } \\
\text { - The project doesn't have to } \\
\text { be instrumental. It aims to } \\
\text { identify designers' emotions } \\
\text { and the impact on their own } \\
\text { design practice, in terms of } \\
\text { decision-making within a } \\
\text { process. }\end{array}$ & $\begin{array}{l}\text { The project will provide case } \\
\text { studies to visualise the } \\
\text { designers' emotions mapped } \\
\text { against time on the project, } \\
\text { with points in the graph } \\
\text { identifying key points of } \\
\text { confusion/stress as well as } \\
\text { design tools to address those. } \\
\text { To account explicitly for what } \\
\text { is valuable information in the } \\
\text { design process for the } \\
\text { designer }\end{array}$ & $\begin{array}{l}\text { Re-map the double diamond } \\
\text { to account for the designer's } \\
\text { emotional experience at each } \\
\text { stage. } \\
\text { To make tangible the tacit, } \\
\text { experiential decisions made } \\
\text { at each stage of a design } \\
\text { process. } \\
\text { To identify the emotional } \\
\text { blocks at key points in a } \\
\text { decision-making process. } \\
\text { Build capacity and resilience } \\
\text { for designers by accounting } \\
\text { for the designer's emotions in } \\
\text { the design process. }\end{array}$ \\
\hline
\end{tabular}




\begin{tabular}{|c|c|c|c|}
\hline 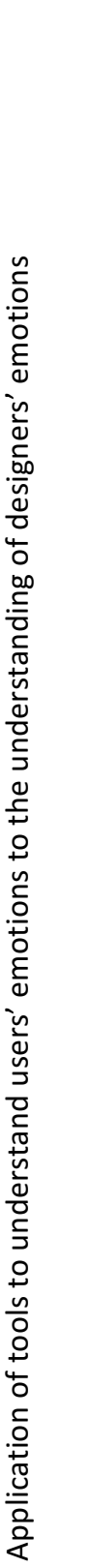 & $\begin{array}{l}\text { Account for the informal, the } \\
\text { non-textual, the emotional, } \\
\text { that exists in the liminal } \\
\text { space between formal } \\
\text { analysis stage and formal } \\
\text { decision-making, that cannot } \\
\text { be captured through } \\
\text { quantitative methods. In } \\
\text { other words, the thoughts, } \\
\text { feelings, and actions that } \\
\text { cannot be recorded or } \\
\text { captured in quantitative } \\
\text { form. The capture of } \\
\text { emotions does not need to } \\
\text { be instrumental. It can simply } \\
\text { allow designers the right to } \\
\text { account for their feelings } \\
\text { during a design process. } \\
\text { Improve understanding of } \\
\text { designers' emotions in the } \\
\text { design process, currently } \\
\text { under-represented. For } \\
\text { example, human-centred } \\
\text { design and emotional design } \\
\text { focus mainly on users' } \\
\text { emotions, while designers } \\
\text { are seen as neutral. } \\
\text { cendress the gaps in human } \\
\text { emotional design, which are } \\
\text { always focussed on users', } \\
\text { not designers', emotions. } \\
\text { Designers are seen as neutral } \\
\text { facilitators. This references } \\
\text { nruno Latour's notion that } \\
\text { nothing and no one can be } \\
\text { objeing completely }\end{array}$ & $\begin{array}{l}\text { Identify the tacit, experiential } \\
\text { decisions made at each stage } \\
\text { of the design process. What } \\
\text { role do informal, non-textual, } \\
\text { narrative and emotional } \\
\text { elements play in the design } \\
\text { process? }\end{array}$ & $\begin{array}{l}\text { Define a framework for } \\
\text { evaluating the impact of } \\
\text { emotions for design process } \\
\text { decision-making } \\
\text { The project can also be } \\
\text { instrumental and } \\
\text { identify/develop tools to } \\
\text { address difficult projects and } \\
\text { how to advise people to } \\
\text { account for difficult emotions } \\
\text { during a decision-making } \\
\text { process that is in stasis or } \\
\text { breakdown. }\end{array}$ \\
\hline 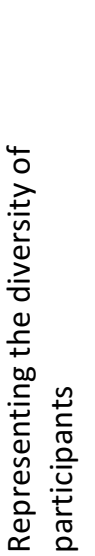 & $\begin{array}{l}\text { - Democratic approach to the } \\
\text { research network. }\end{array}$ & $\begin{array}{l}\text { Draw in expertise from } \\
\text { different subject areas and } \\
\text { contexts. To that end, we are } \\
\text { involving } 10 \text { design academics, } \\
6 \text { academics across business } \\
\text { and management, innovation, } \\
\text { transdisciplinary art, teaching } \\
\text { and learning, and IT; and } 4 \\
\text { industry representatives from } \\
\text { service design, product design, } \\
\text { workshop facilitation, graphics } \\
\text { and fashion and the British } \\
\text { Council PK. }\end{array}$ & $\begin{array}{l}\text { The outcomes should be } \\
\text { applicable as much as possible } \\
\text { to different cultural and } \\
\text { discipline contexts and are } \\
\text { not UK-centric. }\end{array}$ \\
\hline
\end{tabular}

Table 1 Network themes, aims, objectives and impact 
Through the network and addressing the 5 themes above we aim to highlight designer's emotion and tacit knowledge in a cultural context. The capture of emotions does not need to be instrumental. It can simply allow designers the right to account for their feelings during a design process. By not providing an exact methodology for including these aspects, but more a set of possible methods that can be used and modified by the designer, we aim to empower the designer to be confident about including not only their tacit knowledge and emotional experience, but also the tacit understanding that comes from the experience of culturally situated practice.

We see the impact of this research in design higher education as a starting point, partly because of the authors' own backgrounds as well as because of the context in which the project emerged. However, doing this work in education is a way of prototyping techniques that can then be adopted in other contexts, such as design industries, participant facilitation, and design research. By accounting for emotion we are enhancing the innovation potential of the process.

We envision that the outcomes of the network would be a publication of the research findings, to be disseminated in a public event, including:

- A series of case studies/short piece contributions from the network participants (currently have 20 participants from our initial call) to share knowledge across disciplines and geographies regarding designers' emotion and tacit knowledge. This would provide an initial overview of the current consideration of designers' emotion and tacit knowledge and impact in the sectors represented.

- A collection of potential qualitative tools and techniques to account for designers' emotions in the design process. Providing tools to address difficult projects and allowing designers to account for difficult emotions during a decision-making process that is in blockage, stasis or breakdown.

- The initial steps towards a framework for identifying and evaluating the impact of emotions for design process decision-making, by re-mapping the double diamond design process or adapting other design process mapping tools. To make tangible the tacit, experiential decisions made at each stage of a design process and to identify the emotional blocks at key points in a decision-making process.

\section{Discussion and Directions}

With this network, we are aiming to start a focused discussion across geographies and cultures regarding the role and impact of designers' emotions within their own design process. The function of this is to foreground the experiential and emotional domain of designers' practice and examine the role of tacit experiential knowledge in design decision-making.

Our intended outputs are: an index of emotional and experiential aspects; a cross-referencing of those with cross-cultural elements; and an index of qualitative methods examined within the framework of emotion, experience, and culture.

With these initial findings, we will seek to model an application of qualitative methods focusing on emotional and experiential aspects of designers' engagement within a design process. We envision this in the form of an index of potential tools and techniques to help the designer account for type, timing and sequence of emotions during a project, not just for participants but also for him/herself. 
We also consider it relevant to provide a template for designers to map and track their emotions against a project timeline. The project will provide case studies to visualise the designers' emotions mapped against time on the project, with points in the graph identifying key points of confusion/stress as well as design tools to address those. From those, we will also propose a beginning approach to application of this model within the sequential framework of the doublediamond; seeking to identify points within the design process where qualitative methods are most relevant from the designer perspective.

This initial inquiry is a first step towards a bigger and longer project working with democratic approaches within design decision-making processes. We see the consideration of what is collected for analysis and how it is collected and analysed to be fundamental areas to explore towards this greater aim. This project is not about problem-solving but about taking a wider view into all the elements that play a role in a decision-making process in design.

\section{References}

Bang, A. L. (2009). Facilitated articulation of implicit knowledge in textile design. Proceedings of Experiential Knowledge, Method and Methodology.

Bang, A. L. (2011). Emotional Value of Applied Textiles: Dialogue-oriented and participatory approaches to textile design. Retrieved from http://www.forskningsdatabasen.dk/en/catalog/2265178715

Belfiore, E., \& Bennett, O. (2008). The social impact of the arts. Hampshire: Palgrave Macmillan.

Björgvinsson, E., Ehn, P., \& Hillgren, P.-A. (2010). Participatory Design and 'Democratizing Innovation'. In Proceedings of the 11th Biennial Participatory Design Conference (pp. 41-50). New York, NY, USA: ACM. https://doi.org/10.1145/1900441.1900448

Bonnet, J., Lema, D. G. P. D., \& Auken, H. E. V. (2010). The Entrepreneurial Society: How to Fill the Gap Between Knowledge and Innovation. Edward Elgar Publishing.

Boorstin, D. J. (2012). The image: A guide to pseudo-events in America. Vintage.

Buchanan, R. (1992). Wicked Problems in Design Thinking. Design Issues, 8(2), 5-21. https://doi.org/10.2307/1511637

Cheryl Mattingly, M. L. (2000). Learning from Stories: Narrative Interviewing in Cross-cultural Research. Scandinavian Journal of Occupational Therapy, 7(1), 4-14. https://doi.org/10.1080/110381200443571

Damasio, A. (2000). The Feeling Of What Happens: Body, Emotion and the Making of Consciousness (New edition). Vintage.

Damasio, A. (2006). Descartes' Error: Emotion, Reason and the Human Brain. Vintage.

Darwin, C. (1998). The Expression of the Emotions in Man and Animals. Retrieved from http://www.gutenberg.org/ebooks/1227

Dewey, J. (2005). Art As Experience. Perigee Books.

Duque, M. J., Turla, C., \& Evangelista, L. (2013). Effects of Emotional State on Decision Making Time. Procedia Social and Behavioral Sciences, 97, 137-146. https://doi.org/10.1016/j.sbspro.2013.10.214

EKMAN, P., FRIESEN, W. V., \& TOMKINS, S. S. (2009). Facial Affect Scoring Technique: A First Validity Study. Semiotica, 3(1), 37-58. https://doi.org/10.1515/semi.1971.3.1.37

Forlizzi, J. (1997). Designing for Experience: An Approach to Human-centered Design. Department of Design, College of Fine Arts, Carnegie Mellon University,. Retrieved from http://goodgestreet.com/docs/forlizziMDes.pdf

Gill, S. P. (2015). Tacit engagement. In Tacit Engagement (pp. 1-34). Springer.

Groth, C. (2016). Design- and Craft thinking analysed as Embodied Cognition. FormAkademisk Forskningstidsskrift for Design Og Designdidaktikk, 9(1). https://doi.org/10.7577/formakademisk.1481

Gutnik, L. A., Hakimzada, A. F., Yoskowitz, N. A., \& Patel, V. L. (2006). The role of emotion in decision-making: A cognitive neuroeconomic approach towards understanding sexual risk behavior. Journal of Biomedical Informatics, 39(6), 720-736. https://doi.org/10.1016/j.jbi.2006.03.002

Hall, E. T. (1959). The silent language (Vol. 3). Doubleday New York.

Hassenzahl, M. (2010). Experience Design: Technology for all the right reasons. Synthesis Lectures on HumanCentered Informatics, 3(1), 1-95.

Heller, M., \& Haynal, V. (2002). The Doctor's Face: a Mirror of His Patient's Suicidal Projects. In Body Psychotherapy in Progressive and Chronic Disorders. Karger Medical and Scientific Publishers. 
Holmes, J. (2012). The master and his emissary. Psychoanalytic Psychotherapy, 26(2), 160-170. https://doi.org/10.1080/02668734.2012.676994

Ingold, T. (2000). The Perception of the Environment: Essays on Livelihood, Dwelling and Skill. Routledge.

Jordan, P. W. (2000). Designing Pleasurable Products: An Introduction to the New Human Factors. London: Taylor \& Francis.

Kensing, F., \& Blomberg, J. (1998). Participatory Design: Issues and Concerns. Computer Supported Cooperative Work (CSCW), 7(3-4), 167-185. https://doi.org/10.1023/A:1008689307411

Kosonen, K., \& Mäkelä, M. (2012). Designing Platform for Exploring and Reflecting on Creative Process. Procedia - Social and Behavioral Sciences, 45, 227-238. https://doi.org/10.1016/j.sbspro.2012.06.559

Laing, R. (2010). The divided self: An existential study in sanity and madness. Penguin UK.

Latour, B. (2007). Reassembling the social: an introduction to actor-network-theory. Oxford University Press.

Latour, B., Mauguin, P., \& Teil, G. (1992). A Note on Socio-Technical Graphs. Social Studies of Science, 22(1), 33-57. https://doi.org/10.1177/0306312792022001002

Law, J. (1992). Notes on the theory of the actor-network: Ordering, strategy, and heterogeneity. Systems Practice, 5(4), 379-393. https://doi.org/10.1007/BF01059830

Leonard, D., \& Sensiper, S. (1998). The Role of Tacit Knowledge in Group Innovation. California Management Review, 40(3), 112-132. https://doi.org/10.2307/41165946

Linde, C. (2001). Narrative and social tacit knowledge. Journal of Knowledge Management, 5(2), $160-171$. https://doi.org/10.1108/13673270110393202

Long, D. W. D., \& Fahey, L. (2000). Diagnosing cultural barriers to knowledge management. The Academy of Management Executive, 14(4), 113-127. https://doi.org/10.5465/AME.2000.3979820

Lutz, C. (1986). Emotion, Thought, and Estrangement: Emotion as a Cultural Category. Cultural Anthropology, 1(3), 287-309.

Mäkelä, A. M., \& Nimkulrat, N. (2011). Reflection and Documentation in Practice-led Design Research. Nordes, O(4). Retrieved from http://www.nordes.org/opj/index.php/n13/article/view/98

McDonagh, D., Hekkert, P., Erp, J. van, \& Gyi, D. (Eds.). (2003). Design and Emotion. London ; New York: CRC Press.

McGilchrist, I. (2009). The master and his emissary: The divided brain and the making of the western world. Yale University Press.

McLuhan, M. (1964). Understanding Media: The Extensions of Man, London: Rutledge. Google Scholar.

McLuhan, M. (1994). Understanding media: The extensions of man. MIT press.

Niedderer, K., \& Townsend, K. (2014). Designing Craft Research: Joining Emotion and Knowledge. The Design Journal, 17(4), 624-647. https://doi.org/10.2752/175630614X14056185480221

Norman, D. A. (2003). Emotional Design: Why We Love (or Hate) Everyday Things (1st ed.). Basic Books.

Polanyi, M. (2009). The tacit dimension. University of Chicago press.

Rittel, H. W., \& Webber, M. M. (1973). Dilemmas in a general theory of planning. Policy Sciences, 4(2), 155169.

Salovey, P., \& Sluyter, D. J. (2001). Emotional development and emotional intelligence: educational implications. New York: BasicBooks.

Sanders, E. B.-N., \& Stappers, P. J. (2008). Co-creation and the new landscapes of design. Co-Design, 4(1), 5-18.

Schiuma, G. (2011). The Value of Arts for Business. Cambridge University Press.

Schön, D. A. (1985). The design studio: An exploration of its traditions and potentials. International Specialized Book Service Incorporated.

Seitamaa-Hakkarainen, P., Laamanen, T.-K., Viitala, J., \& Mäkelä, M. (2013). Materiality and Emotions in Making. Techne Series - Research in Sloyd Education and Craft Science A, 20(3). Retrieved from https://journals.hioa.no/index.php/techneA/article/view/702

Valtolina, G. G., \& Colombo, C. (2012). Psychological Well-Being, Family Relations, and Developmental Issues of Children Left Behind. Psychological Reports, 111(3), 905-928. https://doi.org/10.2466/21.10.17.PR0.111.6.905-928

Williams, R. (2006). Narratives of knowledge and intelligence ... beyond the tacit and explicit. Journal of Knowledge Management, 10(4), 81-99. https://doi.org/10.1108/13673270610679381

Wright, P., \& McCarthy, J. (2008). Empathy and experience in $\mathrm{HCl}$. In Proceedings of the SIGCHI Conference on Human Factors in Computing Systems (pp. 637-646). New York, NY, USA: ACM.

https://doi.org/10.1145/1357054.1357156 